\title{
Default options and insurance demand
}

\author{
Peter John Robinson ${ }^{\mathrm{a}, *}$, W. J. Wouter Botzen ${ }^{\mathrm{a}, \mathrm{b}, \mathrm{c}}$, Howard Kunreuther ${ }^{\mathrm{c}}$, \\ Shereen J. Chaudhry ${ }^{\mathrm{d}}$ \\ a Department of Environmental Economics, Institute for Environmental Studies, VU University Amsterdam, De Boelelaan 1087, 1081 HV \\ Amsterdam, the Netherlands \\ ${ }^{\mathrm{b}}$ Utrecht University School of Economics (U.S.E.), Utrecht University, P.O. Box 80125, 3508 TC Utrecht, the Netherlands \\ ${ }^{c}$ Risk Management and Decision Processes Center, The Wharton School, University of Pennsylvania, Philadelphia, United States \\ d Booth School of Business, The University of Chicago, Chicago, United States
}

\section{A R T I C L E I N F O}

\section{Article history:}

Received 15 June 2020

Revised 8 December 2020

Accepted 14 December 2020

Available online 7 January 2021

\section{Keywords:}

Choice architecture

Default options

Experience

Flood insurance demand

Loss aversion

\begin{abstract}
A B S T R A C T
Default options may provide a low-cost way of influencing behaviour without modifying incentives and constraining choices between alternatives. However, an improved understanding is needed on whether they are effective when individuals have experience with making the choice in practice and have preferences for specific alternatives. We study whether defaults can be used to increase insurance coverage against low-probability/highimpact risks, like floods, and whether past flood insurance purchases and flooding experience moderate the effect of defaults. Our study uses a naturally occurring difference in experience, comparing the surveyed flood insurance choices of 1,187 homeowners, half of whom are in the Netherlands, where flood insurance penetration rates are low and recent flooding caused minor losses, and the other half of whom are in the United Kingdom (UK), where the opposite is true. We find defaults are effective amongst homeowners with little to no flood-related experience: in the Netherlands defaults increase the likelihood of insuring by between 17 and 18 percentage points. Although there is no overall effect of defaults in the UK, defaults increase flood insurance coverage for risk averse individuals, and those who have no reported previous flood experience and have not purchased flood insurance. Anticipated regret about not having insurance coverage in the event of a flood, and perceptions about the insurance cost explain between 34 and 37 percent of the relationship between the default and flood insurance demand. We discuss policy implications of our findings.
\end{abstract}

(C) 2020 The Authors. Published by Elsevier B.V. This is an open access article under the CC BY license (http://creativecommons.org/licenses/by/4.0/)

\section{Introduction}

Whereas rational economic approaches assume individuals are fully informed and maximize their expected utility, behavioural economics recognizes individuals' cognitive limitations that may lead them to fail to act in their own self-interest (Bhargava and Loewenstein, 2015). Individuals may be more likely to act in accordance with rational economic theory if they have experience related to the decision, because there are opportunities for learning (List, 2003). Within behavioural economics, choice architecture uses subtle changes in decision framing to promote socially and individually beneficial

\footnotetext{
* Corresponding author.

E-mail address: peter.robinson@vu.nl (P.J. Robinson).
} 
decisions (Johnson and Goldstein, 2003; Cohen et al., 2015; Ungemach et al., 2017). However, it has been noted that choice architecture may work better when individuals are less knowledgeable decision makers (Löfgren et al., 2012), because they have not had an opportunity to learn from previous decisions.

Defaults are a type of choice architecture which has received limited attention with respect to insurance against low-probability/high-impact (LPHI) risk, like floods, which is the focus of this study (Kunreuther, 2015; Kunreuther and Pauly, 2018). ${ }^{1}$ Floods are the most frequent and costly natural hazards worldwide and homeowners often underinvest in measures that mitigate these risks (Kunreuther and Pauly, 2004; Browne et al., 2015; Wallemacq, 2018; Kousky, 2018), so there is a rationale for using defaults to encourage individuals to protect themselves against future losses by purchasing insurance. Moreover, Meyer and Kunreuther (2017) suggest developing strategies for improving preparedness for disasters by recognizing decision biases that lead to underinvestment in protective behaviours.

It has been shown that individuals find it difficult to comprehend LPHI risks (Kunreuther et al., 2001). This may increase the tendency of individuals to follow heuristics and their proneness to behavioural biases which can influence the effect of defaults (Thaler and Sunstein, 2008). Therefore, there may be different decision processes that operate when defaults are applied within the LPHI risk context, compared to non-catastrophic risks which have been the focus of multiple studies on defaults (e.g., Johnson et al., 1993, 2013; Coe et al., 2016; Krieger and Felder, 2013). This also highlights the innovation of a dedicated study of defaults under LPHI risk.

We conducted a survey to assess how defaults influenced the way 1187 homeowners made their flood insurance choices. We study homeowners because they are more likely to make flood insurance decisions and be responsible for structural damage to their home if a flood occurs, compared to other subgroups like renters. In one condition, flood insurance coverage was included in an insurance policy and individuals had to opt-out to cancel their coverage. This was compared to an opt-in condition where individuals had to pay additional insurance premiums to include flood coverage in their insurance policy. We define the default effect as the tendency for individuals to maintain the default and not change their choice in decision making (Johnson and Goldstein, 2003). This implies a positive difference in flood insurance purchase between the condition in which flood coverage is provided as opt-out, as opposed to opt-in.

Given the limited attention defaults have received for insurance against LPHI risk, it is also an open question of whether variables related to learning like experience moderate the default effect in this domain. To assess the potential influence of experience on the effectiveness of defaults, we collected data on the impact of opt-in and opt-out policies from two populations that differ in experience: the Netherlands and the United Kingdom (UK). Private flood insurance is purchased by a small fraction of the population in the Netherlands and recent flooding has caused only minor losses, while in the UK flood insurance penetration rates are currently very high and the country has recently experienced a number of damaging flood events. We argue that these types of experience are distinct from experiential factors examined by previous studies, which are related to high levels of individual expertise, e.g., frequent buying and selling experience as well as expert individual knowledge within a specific domain of decision making (List, 2003; Löfgren et al., 2012). Learning effects may differ for LPHI risks since there is little feedback in terms of loss experiences. That is, it is uncertain to what extent individuals learn from the more infrequent experiences of purchasing flood insurance and flooding which may moderate the effectiveness of insurance defaults. These are novel insights provided in the current study.

We control for and test the impact of several features which may influence individuals' response to defaults that may serve as a reference point (Dinner et al., 2011). The status quo often serves as a reference point, and losses are weighted more heavily than gains from the reference point due to loss aversion (Samuelson and Zeckhauser, 1988). Referencedependant subjective expected utility proposed by Sugden (2003) conjectures that if one deviates from the status quo and learns that a better result would have been achieved by maintaining the status quo, she/he will experience regret for not having chosen the ex-post optimal alternative. If an individual anticipates this regret and is regret-averse then he/she will prefer to stay with the status quo ex-ante (Keller et al., 2011; Zhang and Fishbach, 2005; Sautua, 2017).

In keeping with the loss aversion argument of the default effect, the perceived cost of opting out of the default may be influential (Sunstein, 2013). In our setting, individuals may examine the certain cost of purchasing flood insurance relative to the uncertain benefits in terms of reduced flood damages resulting from an unlikely future flood event. If the cost of flood insurance is perceived as high, individuals may decide to stick with the status quo of no flood insurance coverage. Furthermore, general preferences towards risk (which are influenced by loss aversion under prospect theory (Kahneman and Tversky, 1979; Tversky and Kahneman, 1992)) may also impact behaviour with respect to defaults.

Based on the data we collected, we show that subjects demand more flood insurance in the Netherlands if they are assigned to an opt-out rather than an opt-in condition, but we find no overall impact of the default in the UK. Indeed, the contrasting influence of default assignment on flood insurance demand in the Netherlands and the UK is explained by past experience with flooding and previous purchasing of flood insurance. We do find that in the UK there are subgroups for which defaults are effective, i.e., highly risk averse individuals, and those with no reported previous flood experience who have never purchased flood insurance.

The default effect we find in the Netherlands is partially mediated by regret about not purchasing flood insurance coverage in the event of a flood and perceptions about the flood insurance cost. That is, subjects in the opt-out condition are

\footnotetext{
1 Other types of choice architecture have been proposed to increase flood insurance demand, by stretching the time horizon with respect to the likelihood of a future flood occurring (Chaudhry et al., 2020) and by providing information on the severity of flood risk (Bradt, 2019).
} 
more likely to focus on flood damages and regret associated with not insuring, and less likely to focus on the cost of insurance than those assigned to the opt-in condition. This in turn influences whether subjects purchase flood insurance. The mediators of regret and perceived insurance cost may be an indicator of loss aversion in relation to their reference point, which is determined by the default.

The remainder of this paper is structured as follows: Section 2 provides an overview of the flood insurance markets in the Netherlands and the UK. Section 3 describes hypotheses to be tested with motivation from the literature. Section 4 presents the survey design and descriptive statistics. Section 5 details the method used to test the hypotheses and results related to the impact of default options on flood insurance demand. Section 6 discusses these results and provides directions for future research. Section 7 concludes by highlighting the policy implications of the analysis.

\section{Institutional design and comparison}

This section provides an overview of institutional differences between the Netherlands and the UK regarding their flood insurance markets. The two countries have been described as being at opposite ends of the spectrum of flood insurance penetration (Surminski et al., 2015), i.e., penetration rates are currently low in the Netherlands and high in the UK.

Floods very rarely occur in the Netherlands with the last large-scale flood occurring in 1953 when total damage amounted to around 5 percent of Dutch national income (Bos and Zwaneveld, 2017). The most recent flood in the country occurred in 2003 when a dike breach in the village of Wilnis caused $€ 16$ million damage to residential property (Aerts and Botzen, 2011). In contrast, the UK has recently experienced a number of highly publicized flood events, such as those during the winter storms of $2013 / 2014$, which resulted in around $£ 290$ million flood damages (Penning-Rowsell, 2014; Muchan et al., 2015) and 2015/2016, when insured flood damages amounted to approximately £1.3 billion (McCarthy et al., 2016).

Flood insurance is not included in homeowners policies in the Netherlands but this coverage has been offered by a private insurer, Neerlandse, since 2016 on a voluntary basis by more than 1500 insurance agents. ${ }^{2}$ Premium costs are determined on the basis of objective flood risk information provided by Dutch governmental institutions. Today only a very small percentage of homeowners have purchased a flood insurance policy, which may be partially due to a lack of awareness of their flood risk (Suykens et al., 2016). That is, homeowners are perhaps more likely to purchase this insurance if they realize that flood defenses (dikes) provide incomplete protection in the Netherlands. Based on our survey data, only 2 percent of Dutch homeowners report that they currently have flood insurance and $<0.5$ percent have purchased this coverage in the past. $^{3}$ The insured homeowners are also more likely to have suffered flood damage in the past than those who have never purchased a flood insurance policy. 4

The Dutch scheme is distinct from the UK, which has for a long time promoted homeowner responsibility for flood recovery with an emphasis on insurance (Penning-Rowsell and Priest, 2015). Private flood insurance in the UK was established in 1961, and is purchased as part of standard home insurance policies (Paudel et al., 2012). Since the 1970s, penetration rates have been quite high in part due to an agreement between government and the insurance industry that mortgage holders are required by financial institutions to carry flood insurance, although those at very high risk were excluded from the agreement (Huber, 2004; Penning-Rowsell et al., 2014).

The UK has also made efforts over the years to enhance flood insurance availability for high risk homeowners. For example, in the past insurers agreed to provide flood insurance to homeowners up to a 1 in 75 years return period (Surminski and Eldridge, 2017), and a recently established reinsurance pool (Flood $R e$ ) is used to subsidize the premiums paid by high risk households (Surminski, 2018).

According to our sample data, 39 percent of homeowners in the UK report that they currently have flood insurance and 6 percent had flood insurance in the past. This is consistent with expectations that a much higher percentage of homeowners will have purchased flood insurance in the UK than the Netherlands. In practice, the percentage of homeowners who actually carry flood insurance is much higher ( 95 percent) (HM Government, 2016). Therefore it is likely that many homeowners in our UK sample carry flood insurance but are not aware of it. Indeed it is not uncommon for homeowners to misreport their insurance status in surveys (Andor et al., 2020). As in the Netherlands, homeowners who know they currently have flood insurance, or held it in the past are also more likely to have been flooded in the past. ${ }^{5}$

\section{Hypotheses}

A few studies have tested the impact of default assignment on insurance decisions. Johnson et al. (1993) examined changes in legislature in two states in the US regarding whether auto insurance policies retained a right to sue for pain and suffering resulting from a car accident. A higher percentage of motorists in Pennsylvania, where the default policy included the right to sue, have purchased the right to sue compared to motorists in New Jersey, where the default policy

\footnotetext{
2 These figures are provided on the Neerlandse website (www.neerlandse.co.uk).

3 The exact percentage of homeowners who have actually purchased flood insurance is not available in the Netherlands according to the publicly available information.

${ }^{4}$ Only 1 percent of homeowners who report to have never purchased flood insurance report to have suffered flood damage to their property in the past, compared to 58 percent for those who currently have or previously had flood insurance.

51 percent of homeowners in the UK who report to have never held flood insurance, also report to have been flooded in the past. Whereas, 19 percent of homeowners who report to hold flood insurance or held it in the past, report to have been flooded in the past.
} 
did not include this right. Johnson et al. (2013) also found that individuals are more likely to choose cost-effective health insurance policies if they are preselected. Coe et al. (2016) find that compared to active choice, providing life insurance as a default option increased the rate of coverage. Krieger and Felder (2013) showed that default assignment to a health insurance policy where the individual pays 0 percent of medical treatment costs positively impacted coverage levels, compared to active choice. Overall it seems that providing insurance as the default increases demand for coverage.

H1: More individuals will purchase flood insurance if it is included in an insurance policy by default and individuals must opt-out to cancel their coverage, than in an opt-in condition where individuals must pay additional insurance premiums to include flood coverage.

However, this effect may be a function of the degree of experience an individual has in a given decision domain. The impact of health insurance default policies on coverage rates found by Krieger and Felder (2013) dissipated over later periods of their repeated decision making experiment. Löfgren et al. (2012) found that experienced individuals (environmental economists attending a conference), who are more knowledgeable about the decision at hand, are not influenced by carbon offsetting default assignments. In an earlier study, List (2003) showed that anomalies like the endowment effect do not occur amongst experienced consumers who have high levels of expertise in the decision domain, compared to those who have no market experience. ${ }^{6}$ Apparently, unexperienced consumer behaviour may be better explained by theories that incorporate psychological aspects like reference dependence and loss aversion, such as prospect theory (Kahneman and Tversky, 1979; Tversky and Kahneman, 1992) and reference-dependant subjective expected utility (Sugden, 2003), whereas experienced consumer behaviour can be explained by conventional (rational) economic theory (List, 2004). ${ }^{7}$

In this paper we distinguish between two types of past experience: purchasing flood insurance and suffering flood damage. Note that we do not hypothesize that all homeowners who are insured against flooding will choose to purchase flood insurance in the survey. Homeowners may be required to carry flood insurance as part of their mortgage requirements (as in the UK), but given the option would rather face their flood risk uninsured. We conjecture that UK homeowners are more likely to have focused on their flood insurance preferences than Dutch homeowners, because nearly every homeowner in the UK has this coverage whereas the penetration rate in the Netherlands is close to zero (see Section 2). Overall, we expect that homeowners who have purchased flood insurance know more about the perceived benefits (or costs) of insurance. This type of learning by UK homeowners would create a stronger preference for (or against) flood insurance than for homeowners in the Netherlands who have less experience purchasing flood insurance. As a result, experience may increase decisiveness which would lead to less inertia and lower prevalence of the default effect (Sautua, 2017; Brown et al., 2016).

There are also reasons to suspect that the default may backfire for experienced individuals. It has been argued that policies that cause a perceived threat to autonomy may lead to reactance, i.e., resistance to such policies and a counter-response (Brehm, 1966; Pavey and Sparks, 2009). Indeed, there is evidence to suggest that individuals who have strong preferences for alternatives may perceive opt-out policies as an infringement on their autonomy, and attempt to reinstate this by opting out, whereas this effect does not occur amongst individuals who are previously undecided on their preferences (Reiter et al., 2012). Note that although defaults preserve actual autonomy, for reactance to occur individuals need only perceive a pressure to change their behaviour (Clee and Wicklund, 1980). That is, it is a restriction on perceived autonomy that is a prerequisite to reactance, it is not necessary that actual freedom is limited (de Jonge et al., 2018).

H2: Individuals who have purchased private flood insurance are either less prone to the default effect, or purchase coverage more often in the opt-in than the opt-out condition.

We also conjecture that homeowners who have experienced flood damage have learned about the advantages and disadvantages of (not) having flood insurance, and hence are likely to have strong pre-defined preferences as to whether or not to purchase coverage. ${ }^{8}$ Therefore, we make a similar prediction for experience with flood damage as for experience with purchasing flood insurance.

H3: Individuals who have experience with flood damage are either less prone to the default effect, or purchase coverage more often in the opt-in than the opt-out condition.

It has been hypothesized that default options represent a reference point from which individuals judge gains and losses (Dinner et al., 2011). Because losses are weighted more heavily than gains in decisions (loss aversion) (Kahneman et al., 1991), a change in the default option can lead to a change in one's decision. Indeed, loss aversion has already been suggested by a number of authors as a root cause of default effects (Smith et al., 2013; Johnson et al., 2002; Jachimowicz et al., 2019; Sunstein, 2013)..$^{9}$

\footnotetext{
6 The endowment effect refers to an increase in the value of a good when it is part of an individual's endowment (Thaler, 1980).

7 Plott and Zeiler (2005) find in a related study that once subjects are given adequate training and practice with experimental procedures, and incentive compatible remuneration is provided, that the endowment effect is eliminated.

8 Regarding the impact of flooding experience on flood insurance demand in general, previously flooded respondents may be more inclined to not purchase coverage due to premium increases which have followed flood events in the past in the UK (Institute and Faculty of Actuaries, 2016). According to a report written after the 2007 floods in England, some premiums were quadrupled and excess levels were raised by up to 30,000 (Pitt, 2008). On the other hand, previously flooded respondents may be more likely to purchase insurance due to flood risk being more available in their minds (Tversky and Kahneman, 1974).

${ }^{9}$ In the context of our experiment loss aversion may be more relevant than alternative explanations of default effects, such as whether defaults are perceived as an implicit endorsement (McKenzie et al., 2006), or whether the process of deciding between alternatives requires significant effort, whereas sticking with the default is perceived as relatively effortless (Johnson and Goldstein, 2003).
} 
Table 1

Summary of survey conditions.

\begin{tabular}{llllll}
\hline \multirow{2}{*}{$\begin{array}{l}\text { Country } \\
\text { Conditions }\end{array}$} & \multicolumn{2}{l}{ Netherlands } & & UK & \\
\cline { 2 - 3 } \cline { 5 - 6 } \cline { 5 - 6 } & opt-in & opt-out & & opt-in & opt-out \\
\hline Subjects & 300 & 299 & & 297 & 291 \\
\hline
\end{tabular}

In our analysis we examine variables which can (partially) account for the relationship between the nature of the default and flood insurance demand. If loss aversion is the cause of the default effect, this implies that individuals will focus on different sources of loss in the opt-in versus the opt-out condition since they will have different reference points. Individuals in the opt-in insurance condition must pay an extra premium to add a flood insurance component to their insurance policy. The additional costs may loom large (see also Prelec and Loewenstein (1998), who suggest that when making purchases, individuals can experience an immediate "pain of paying", which reduces the pleasure associated with consumption). This may lead individuals to stick with the default (no flood insurance coverage). To assess this, we use perceived insurance premium, which measures whether individuals find the flood insurance cost too expensive, as a proxy for how individuals feel about the certain cost of purchasing flood insurance, which is a loss from a no flood insurance coverage default. In contrast, in an opt-out condition, individuals may instead focus on the disadvantages of removing the flood insurance component in terms of potential flood losses, and the regret one might feel in the event of an uninsured loss. For this reason, anticipated regret is used as a proxy for how individuals feel about potential uninsured flood losses if individuals were to opt-out of a flood insurance coverage default. We predict the following based on loss aversion and reference dependence:

H4: The perceived cost of flood insurance and anticipated regret about not purchasing flood insurance coverage should a flood occur mediate the impact of the default assignment on flood insurance demand.

We also examine whether risk preferences influence the strength of the relationship between the default and flood insurance demand. Loss aversion is a component of risk preference under prospect theory (Kahneman and Tversky, 1979; Tversky and Kahneman, 1992). Moreover, it has been contended that most risk aversion empirically observed is caused by loss aversion (Wakker, 2010), which implies that a general measure of risk aversion could be picking up primarily on loss aversion. However, this examination should be treated as exploratory, because a general measure of risk preferences, such as the one we use, cannot parse out loss aversion from other components of risk preference (probability weighting and utility curvature).

\section{Survey design and descriptive statistics}

We sampled 599 homeowners in the Netherlands and 588 homeowners in the UK through the survey company Multiscope (www.multiscope.nl) during February $2019 .{ }^{10}$ We employed a non-incentivized survey given that incentivizing large losses is complicated practically and perhaps unethical (Etchart-Vincent, 2009). Moreover, it is not clear if it results in large biases (Robinson and Botzen, 2019) since individuals have a low incentive to lie. It has also been shown that endowing respondents with money, which would be used for them to make incentivized choices, can distort risk attitudes (Thaler and Johnson, 1990). An advantage of our sample over student samples often used in lab experiments is that we examine homeowners facing flood risk and making insurance purchase choices in real life which ensures higher external validity. Note that we did not include practice rounds in the survey because this experience may mute any default effect we would expect to find for previously unexperienced respondents (Krieger and Felder, 2013).

After some initial socio-economic questions, subjects were asked to: "Imagine that you have just moved in to a new home in the Netherlands (United Kingdom) which you purchased for $€ 260,000$ ( $£ 227,500) .{ }^{11}$ Your new home is at risk of flooding. The government will not reimburse you for any flood damage you suffer if you do not insure your home."

Homeowners in the Netherlands and UK were randomly assigned to face either an opt-in condition (300 and 297 subjects, respectively) or an opt-out condition (299 and 291 subjects, respectively). The conditions used the following wording to describe the flood probability: "Every year there is a $\mathbf{1}$ in $\mathbf{1 2 5 0}$ chance that your new home will be flooded." The opt-in condition asked subjects whether they would like to add flood coverage to a pre-purchased insurance policy which covers fire and burglary related losses. The opt-out condition asked subjects whether they would like to remove flood coverage from a pre-purchased insurance policy which covers flood, fire and burglary related losses. Fig. 1 presents the way in which flood insurance demand was elicited over the opt-in and opt-out conditions. Table 1 provides an overview of the conditions.

Naturally there may be some variation in actual flood risks faced by homeowners within both the Netherlands and the UK. We chose one probability and damage amount in order to standardize the decision environment, and to enable the comparison of default effects between the two countries. Probability 1 in 1250 reflects the flood probability for homes situated in the river delta of the Netherlands, based on river-dike safety norms. The average damage from flooding per residence for homes facing the 1 in 1250 probability was calculated in Botzen and van den Bergh (2009; 2012) based on

\footnotetext{
10 A pre-test was conducted initially to refine the survey instructions.

$11 € 260,000$ is the approximate average purchase price for a property in the Netherlands (Statistics Netherlands, 2018). For the UK version of the survey, $€ 260,000$ is replaced by $£ 227,500$, which is equal to the Dutch average based on purchasing power parity figures.
} 
Every year there is a $\mathbf{1}$ in $\mathbf{1 , 2 5 0}$ chance that your new home will be flooded. The estimated damage from a flood to your new home is $\mathbf{6 8 0 , 0 0 0}(\mathbf{( 7 7 0 , 0 0 0 )}$.

You have purchased an insurance policy from your insurance agent.

Opt-in

This standard policy covers fire and burglary related losses for the price of $€ 128$ (£112) per year.

You may add flood coverage to your insurance policy and it will increase your annual insurance premiums by $€ 64$ (£56) (resulting in a total insurance cost of $€ 192$ (£168)).

Do you choose to add flood coverage to your insurance policy? Yes/No

Opt-out

This standard policy covers flood, fire and burglary related losses for the price of $€ 192$ ( $£ 168$ ) per year.

You may remove flood coverage from your insurance policy and it will decrease your annual insurance premiums by $€ \mathbf{6 4}$ (£56) (resulting in a total insurance cost of $€ 128$ (£112)).

Do you choose to remove flood coverage from your insurance policy? Yes/No

Fig. 1. Flood insurance demand elicitation over the opt-in and opt-out conditions.

the flood damage model of Wouters (2005). In today's price levels this is $€ 80,000$ (rounded). Moreover, the flood insurance premium was set at the actuarially fair (€64) level (equal to probability multiplied by damage) though individuals were not told this explicitly. We provide the insurance costs with and without flood insurance, so that potential default effects are less likely to be due to subjects' calculation capacities ${ }^{12}$ or the mental burden of making a choice. ${ }^{13}$

\footnotetext{
${ }^{12}$ One may question whether default effects are related to numerical ability, which may include probabilistic understanding. We ran an interaction analysis between answers to a question from the Frederick (2005) Cognitive Reflection Test (CRT): "A bat and a ball cost $€$ (or $£$ )1.10 in total. The bat costs $€($ or $£) 1.00$ more than the ball. How much does the ball cost?" (correct answer $=1$; incorrect answer $=0$ ), and the default. Note that although the CRT was initially developed to measure cognitive reflection, it has also been shown to be a reliable measure of numerical ability (Campitelli and Gerrans, 2014; Weller et al., 2013; Thomson and Oppenheimer, 2016). Individuals who answered the bat and ball question correctly are no more or less responsive to the default based on a Probit model analysis of the likelihood of flood insurance purchase with independent dummy variables opt-out, correct answer and an interaction between the two (for the Netherlands: coefficient estimate on correct answer $=-0.02$, p-value $=0.92$; coefficient estimate on opt-out $=0.47$, $\mathrm{p}$-value $=0.00$; coefficient estimate on correct answer $\mathrm{X}$ opt-out $=0.16, \mathrm{p}$-value $=0.51$; for the UK: coefficient estimate on correct answer $=0.11$, $\mathrm{p}$ value $=0.65$; coefficient estimate on opt-out $=-0.07$, p-value $=0.62$; coefficient estimate on correct answer X opt-out $=0.33$, $\mathrm{p}$-value $=0.34$ ).

${ }^{13}$ We also examined interactions between answers to the question: "How difficult or easy was it to make a choice about including flood coverage in your insurance policy?" (very difficult $=1$; difficult $=2$; not difficult $/$ not easy $=3$; easy $=4$; very easy $=5$ ), and the default. Individuals who found the decision easier were no more or less responsive to the default based on a Probit model analysis of the likelihood of flood insurance purchase with independent dummy variables opt-out, decision ease and an interaction between the two (for the Netherlands: coefficient estimate on decision ease $=0.07$, $\mathrm{p}$-value $=0.34$; coefficient estimate on opt-out $=0.41$, $\mathrm{p}$-value $=0.30$; coefficient estimate on decision ease $\mathrm{X}$ opt-out $=0.03, \mathrm{p}$-value $=0.79$; for the UK:
} 
Table 2

Summary of variables by country.

\begin{tabular}{|c|c|c|c|c|}
\hline Dependant variable & Measurement & Coding & Netherlands $\mathrm{M}(\mathrm{SD})^{\mathrm{a}}$ & UK M (SD) \\
\hline $\begin{array}{l}\text { Flood insurance } \\
\text { demand }\end{array}$ & $\begin{array}{l}\text { Dummy variable measure of flood } \\
\text { insurance demand. }\end{array}$ & Insure $=1$ and do not insure $=0$ & 0.61 & 0.83 \\
\hline Condition & Measurement & Coding & Netherlands M (SD) & UK M (SD) \\
\hline Opt-out & $\begin{array}{l}\text { Dummy variable measure of default } \\
\text { assignment. }\end{array}$ & Opt-out $=1$ and opt-in $=0$ & 0.50 & 0.49 \\
\hline $\begin{array}{l}\text { Questions related to } \\
\text { flood insurance choice }\end{array}$ & Measurement & Coding & Netherlands M (SD) & UK M (SD) \\
\hline Regret & $\begin{array}{l}\text { I would feel regret about not } \\
\text { purchasing flood insurance coverage if } \\
\text { a flood were to occur next year. }\end{array}$ & $\begin{array}{l}\text { Strongly disagree }=1 \text { to strongly } \\
\text { agree }=7^{\mathrm{b}}\end{array}$ & $5.55(1.58)$ & $6.00(1.44)$ \\
\hline Insurance cost & $\begin{array}{l}\text { The annual flood insurance cost } € 64 \\
\text { (£56) is too expensive. }\end{array}$ & $\begin{array}{l}\text { Strongly disagree }=1 \text { to strongly } \\
\text { agree }=7\end{array}$ & $4.08(1.72)$ & $3.62(1.63)$ \\
\hline Flood experience & Measurement & Coding & Netherlands M (SD) & UK M (SD) \\
\hline Flooding experience & $\begin{array}{l}\text { Dummy variable measure of previous } \\
\text { flood. }\end{array}$ & $\begin{array}{l}\text { Flooded in the past }=1 \text { and not } \\
\text { flooded in the past }=0\end{array}$ & 0.02 & 0.09 \\
\hline $\begin{array}{l}\text { Insurance purchasing } \\
\text { experience }\end{array}$ & Measurement & Coding & Netherlands M (SD) & UK M (SD) \\
\hline Hold insurance & $\begin{array}{l}\text { Dummy variable measure of holding } \\
\text { flood insurance. }\end{array}$ & $\begin{array}{l}\text { Hold flood insurance }=1 \text { and do not } \\
\text { hold flood insurance }=0\end{array}$ & 0.02 & 0.39 \\
\hline Held insurance & $\begin{array}{l}\text { Dummy variable measure of held } \\
\text { flood insurance in the past. }\end{array}$ & $\begin{array}{l}\text { Held flood insurance in the past }=1 \\
\text { and did not hold flood insurance in } \\
\text { the past }=0\end{array}$ & 0.00 & 0.06 \\
\hline Trust in flood defenses & Measurement & Coding & Netherlands M (SD) & UK M (SD) \\
\hline Trust & $\begin{array}{l}\text { I am confident that the dikes (flood } \\
\text { defenses) in the Netherlands (United } \\
\text { Kingdom) are well maintained. }\end{array}$ & $\begin{array}{l}\text { Strongly disagree }=1 \text { to strongly } \\
\text { agree }=7\end{array}$ & $5.30(1.26)$ & $3.89(1.37)$ \\
\hline $\begin{array}{l}\text { Socio-economic } \\
\text { variables and } \\
\text { preferences }\end{array}$ & Measurement & Coding & Netherlands M (SD) & UK M (SD) \\
\hline Age & Age in years & Age in years & $54.47(13.59)$ & $50.35(14.76)$ \\
\hline Male & Dummy variable measure of gender. & Male $=1$ and female $=0$ & 0.53 & 0.53 \\
\hline Higher education $^{c}$ & $\begin{array}{l}\text { Dummy variable measure of higher } \\
\text { education. }\end{array}$ & $\begin{array}{l}\text { Higher education }=1 \text { and no higher } \\
\text { education }=0\end{array}$ & 0.52 & 0.51 \\
\hline Risk preference & General willingness to take risks. & $\begin{array}{l}\text { Completely unwilling to take risks }=1 \\
\text { to very willing to take risks }=11\end{array}$ & $5.72(2.07)$ & $5.44(2.41)$ \\
\hline
\end{tabular}

Immediately following the flood insurance decision, subjects were asked a number of questions based on how they made their choices, flood insurance purchasing and flooding experience, trust in flood defenses as well as to elicit socio-economic variables and risk preferences (see Table 2). We asked subjects "For the following questions please think about how you made your choice about whether or not to add (remove) flood coverage to (from) your insurance policy", then consistent with studies by Robinson and Botzen (2019) and Keller et al. (2011), anticipated regret was elicited by asking subjects their extent of agreement (on a 7-point scale) with the statement: "I would feel regret about not purchasing flood insurance coverage if a flood were to occur next year." To determine the degree to which subjects found the survey flood insurance costs expensive, we included the item: "The annual flood insurance cost $€ 64$ ( $£ 56$ ) is too expensive."

Regarding the experiential variables, in the Netherlands we included the following: "Currently flood insurance is not part of home insurance or home contents insurance policies in the Netherlands. However, homeowners can purchase a separate insurance policy that covers their flood risk. Have you ever purchased this insurance policy that covers flood risk?". Response options: "Yes, I currently hold this separate insurance policy that covers flood risk"; "Yes, I held this separate insurance policy that covers flood risk in the past, but I decided to cancel my policy"; "No, I never held this separate insurance policy that covers flood risk". In the UK we asked subjects a slightly modified version: "Currently flood insurance is often included in home insurance policies in the United Kingdom. So homeowners can purchase a home insurance policy that covers their flood risk. Have you ever purchased this home insurance policy that covers flood risk?" Response options: "Yes, I currently hold this home insurance policy that covers flood risk"; "Yes, I held this home insurance policy that covers flood risk in the past, but I decided to cancel my policy"; "No, I never held this home insurance policy that covers flood risk". The two versions of this question are in line with the way in which flood insurance is currently being sold in the Netherlands and

coefficient estimate on decision ease $=0.16, \mathrm{p}$-value $=0.04$; coefficient estimate on opt-out $=-0.61$, $\mathrm{p}$-value $=0.17$; coefficient estimate on decision ease $\mathrm{X}$ opt-out $=0.15$, p-value $=0.17$ ). 
the UK, respectively. To determine whether subjects had experienced flooding in the past (yes/no), we asked: "Has your home been flooded in the past when you were living in it?"

To examine subjects' extent of trust in flood defenses, we included the item: "I am confident that the dikes (flood defenses) in the Netherlands (United Kingdom) are well maintained." The item is similar to the way in which trust in flood defenses was measured amongst Dutch residents in Terpstra (2011). We use trust to proxy for flood risk perceptions amongst homeowners. Other measures of flood risk perception, like the perceived likelihood of flooding at one's current home, may not apply to the new home we ask subjects to imagine in the survey because this variable relates specifically to where the individual is currently living. Whereas, a more general indicator of flood risk perceptions (elicited trust in flood defenses) applies to the survey flood risk, and is not specific to one's current home. We assume that subjects who have higher trust in their country's flood defenses have lower general flood risk perceptions, consistent with Terpstra (2011).

Risk preferences were elicited following Dohmen et al. (2011), who asked respondents to rate their willingness to take risks in general: "How do you see yourself: are you generally a person who is willing to take risks or do you try to avoid taking risks? Please use a scale from 0 to 10 , where a 0 means you are 'completely unwilling to take risks', and a 10 means you are 'very willing to take risks'. You can also answer values in-between to indicate where you fall on the scale." Note that data for this variable is coded from 1 to 11 rather than 0 to 10 (see Table 2). The survey-based measure of Dohmen et al. (2011) is validated in the sense that it is strongly correlated with the way in which individuals make choices in paid lottery experimental decisions. Moreover, the authors showed that the measure is a good all-round predictor of a range of risky behaviours in practice.

It is notable that flood insurance demand is significantly higher in the UK than in the Netherlands (Chi-squared test statistic $=71.97$, p-value $=0.00$ ). Compared to the Netherlands, UK respondents are also more likely to feel regret about not purchasing flood insurance coverage if a flood were to occur next year (Wilcoxon rank-sum test statistic $=-6.10$, $\mathrm{p}$ value $=0.00$ ), and less likely to deem the flood insurance cost as too expensive (Wilcoxon rank-sum test statistic $=4.68$, $\mathrm{p}$-value $=0.00$ ). They also trust less that their flood defenses are well maintained (Wilcoxon rank-sum test statistic $=16.96$, p-value $=0.00$ ).

The increased willingness of UK respondents to purchase flood insurance may be due to potential regret should they experience flood damage in the future given that the country has experienced flood events in recent years that have been given significant media coverage (Cologna et al., 2017). Moreover, it is reasonable to assume that homeowners are more aware that flood insurance can be purchased in the UK than the Netherlands. Overall the percentage of respondents whose home is reported to have been flooded in the past is 2 percent in the Netherlands, whereas the corresponding figure for the UK is 9 percent. The differences in trust in flood defenses and perceptions about the flood insurance cost between the Netherlands and the UK are also unsurprising given the differences in flooding experience and media attention given to flooding events.

Apart from the perceived cost of flood insurance and anticipated regret about not purchasing flood insurance coverage variables, which are treated as mediators in Section 5, there are no significant differences in the flood experience, insurance purchasing experience, trust in flood defenses, socio-economic and preferences variables between treatment conditions (opt-in and opt-out) within the Netherlands (p-values $>0.05$ ). Furthermore, within the UK there are also no significant differences for these variables between treatment conditions except for the proportion of respondents who indicated that they currently hold flood insurance, which is higher in the opt-out than the opt-in condition (Chi-squared test statistic $=8.91$, p-value $=0.00$ ). However, given that we find on average no significant difference in flood insurance demand by treatment condition within the UK (Section 5), the relation between treatment condition and flood insurance demand is not driven by the reported holding of flood insurance.

\section{Results}

Section 5.1 examines the impact of default assignment on flood insurance demand via a simple graphical analysis. Section 5.2 provides a regression analysis of the impact of default assignment that enables one to control for other observable characteristics such as the moderating roles of flooding experience, reported insurance purchasing experience and risk preference on the influence of default assignment, and the role of variables regret and insurance cost in mediating the influence of default assignment. ${ }^{14}$ We consider flooding experience, reported insurance purchasing experience and risk preference as moderators because we expect these variables may influence the strength of the relation between default assignment and flood insurance demand. In contrast, we expect regret and insurance cost to (partially) account for the relation between default assignment and flood insurance demand, therefore we consider them as mediators.

\subsection{Graphical analysis}

Fig. 2 displays the effect of the default i.e., the difference in the proportion of flood insurance purchase between the opt-out and opt-in conditions, by country. The figure is based on a Probit model analysis of the likelihood of flood insurance purchase with independent dummy variables opt-out, UK and an interaction between the two. According to the analysis,

\footnotetext{
14 The explanatory variables were checked for high correlations. All correlation coefficients are lower than 0.5 , therefore multicollinearity should not pose a problem for our analysis (Hensher et al., 2005).
} 


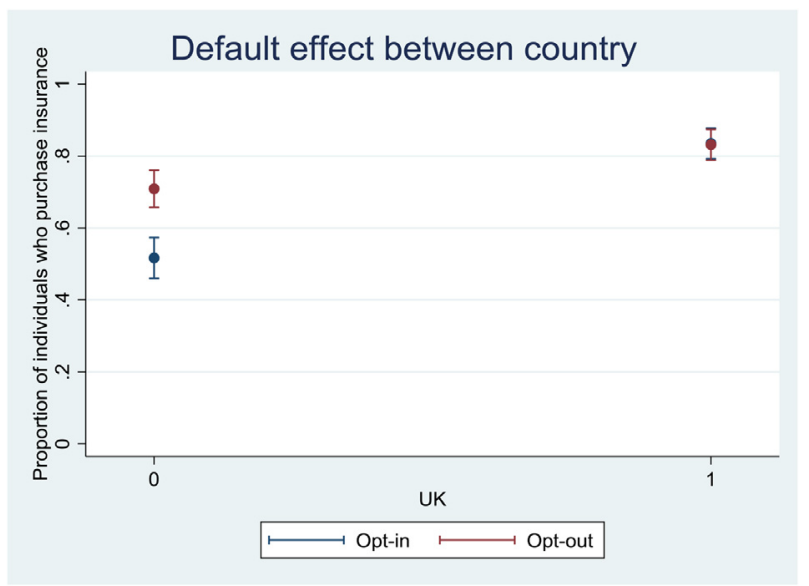

Fig. 2. Default effect between the Netherlands $(\mathrm{UK}=0)$ and the UK $(\mathrm{UK}=1)$.

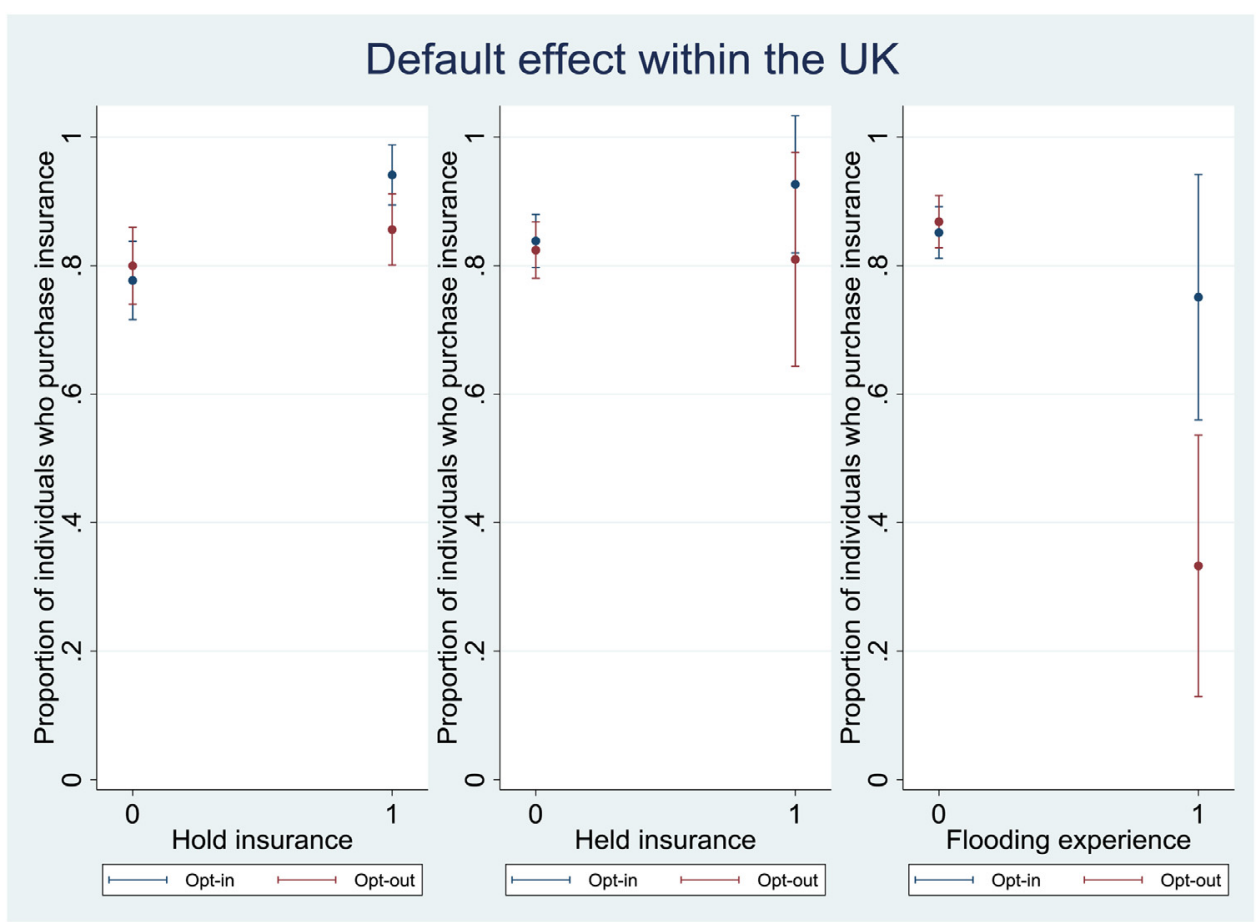

Fig. 3. Default effect within the UK over whether subjects report to currently hold flood insurance (hold insurance $=1$ ) and not (hold insurance $=0$ ), whether subjects report to have held flood insurance in the past (held insurance $=1$ ) and not (held insurance $=0$ ), and whether subjects report to have been flooded in the past (flooding experience $=1$ ) and not (flooding experience $=0$ ).

there is a significant default effect (a positive difference in the proportion of insurance purchase between opt-out and opt-in) in the Netherlands, but an insignificant default effect in the UK (coefficient estimate on UK dummy $=0.93$, p-value $=0.00$; coefficient estimate on opt-out $=0.51$, p-value $=0.00$; coefficient estimate on UK dummy X opt-out $=-0.52$, $\mathrm{p}$-value $=0.00$ ). Therefore, the results are consistent with our expectations that the default effect is higher in the Netherlands, where flood insurance penetration rates and flooding experiences are lower in practice than the UK. Moreover, flood insurance demand in the survey is higher overall in the UK than in the Netherlands.

Fig. 3 shows the default effect in the UK over the variables hold insurance, held insurance and flooding experience. The figure is based on a Probit model analysis of the likelihood of flood insurance purchase within the UK with independent dummy variables opt-out, hold insurance, held insurance and flooding experience, as well as interactions between the latter three variables and opt-out. ${ }^{15}$ The analysis shows that for those who report to hold flood insurance, there is a

\footnotetext{
15 In a separate more elaborate analysis we examined interactions between hold insurance and flooding experience as well as held insurance and flooding experience. These interactions are insignificant according to a Probit model analysis (coefficient estimate on hold insurance $=0.88$, p-value $=0.00$; coefficient
} 


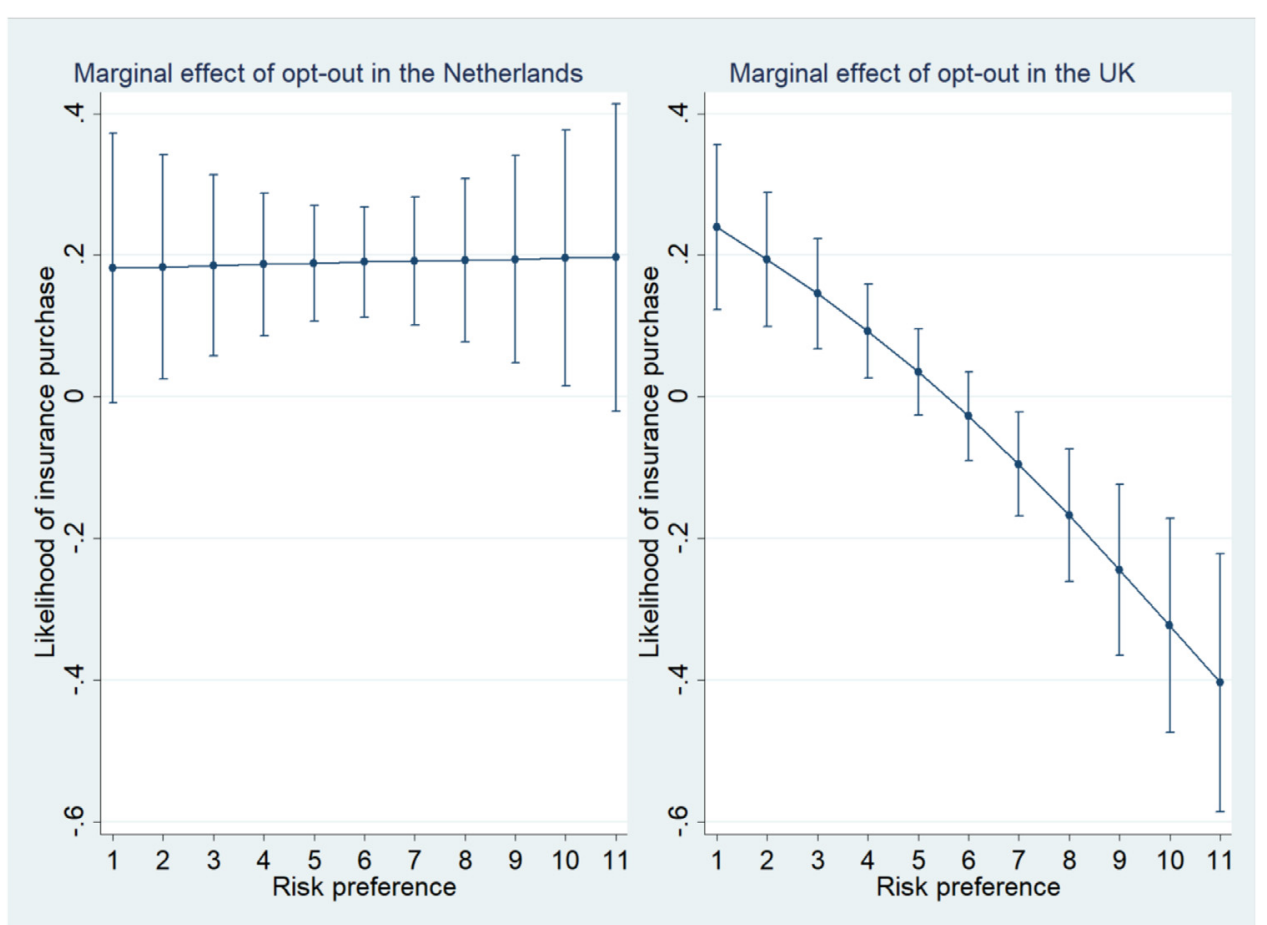

Fig. 4. Marginal effect of opt-out on the likelihood of flood insurance purchase across levels of risk preference within the Netherlands and the UK; higher (lower) values represent more risk seeking (aversion).

marginally significant negative difference in flood insurance demand in the survey between opt-out and opt-in (coefficient estimate on hold insurance $=0.81$, p-value $=0.00$; coefficient estimate on opt-out $=0.25$, p-value $=0.12$; coefficient estimate on hold insurance X opt-out $=-0.55$, p-value $=0.08$ ). Furthermore, there is an insignificant difference in flood insurance purchase between opt-out and opt-in for those who report to have held flood insurance and not (coefficient estimate on held insurance $=0.49$, $\mathrm{p}$-value $=0.25$; coefficient estimate on opt-out $=0.25$, $\mathrm{p}$-value $=0.12$; coefficient estimate on held insurance X opt-out $=-0.55, \mathrm{p}$-value $=0.33$ ). The confidence intervals are large when held insurance $=1$, because the subgroup of subjects who report to have held insurance in the past (and do not hold it now) is rather small (6 percent of subjects in the UK). Lastly, there is a negative significant difference in flood insurance demand between opt-out and opt-in for those who have flooding experience in the UK (coefficient estimate on flooding experience $=-0.39$, $\mathrm{p}$-value $=0.27$; coefficient estimate on opt-out $=0.25$, p-value $=0.12$; coefficient estimate on flooding experience $\mathrm{X}$ opt-out $=-1.17$, $\mathrm{p}$-value $=0.01$ ). Overall, we believe that individuals who have experience purchasing flood insurance, and with flooding, may perceive opt-out policies as an infringement on their autonomy. This may have caused individuals to forgo coverage in an attempt to reinstate their autonomy. Opt-in policies are likely to be perceived as a lower threat to autonomy (Reiter et al., 2012). These effects are similar to Reiter et al. (2012), who studied whether parental consent for having their sons vaccinated at school is higher in an opt-out vs. an opt-in condition. amongst parents who have a preference for having their sons vaccinated in the next year, consent was higher in the opt-in condition than the opt-out condition.

Fig. 4 displays the marginal effect of opt-out on the likelihood of flood insurance purchase across levels of risk preference within the Netherlands and the UK. The figure is based on a Probit model analysis of the likelihood of flood insurance purchase within the Netherlands and the UK separately, with independent dummy variable opt-out and risk preference, as well as an interaction between the two. There is no evidence of an interaction effect in the Netherlands because the marginal effect of opt-out on the likelihood of flood insurance purchase remains fairly constant across levels of risk preference (coefficient estimate on risk preference $=-0.02$, $\mathrm{p}$-value $=0.55$; coefficient estimate on opt-out $=0.50, \mathrm{p}$-value $=0.12$; coefficient estimate on risk preference X opt-out $=0.00, \mathrm{p}$-value $=0.99$ ). In the UK there is a significant default effect for risk averse subjects, i.e., compared to opt-in, the opt-out condition leads to higher flood insurance demand. However, the more comfortable a subject is with risk, the lower the impact of the default, and for those with the highest tolerance for risk, the opt-out condition actually "backfires" and decreases flood insurance demand relative to opt-in (coefficient estimate on risk

estimate on held insurance $=0.23$, p-value $=0.61$; coefficient estimate on flooding experience $=-0.30$, $\mathrm{p}$-value $=0.73$; coefficient estimate on hold insurance $\mathrm{X}$ flooding experience $=-0.31$, $\mathrm{p}$-value $=0.73$; coefficient estimate on held insurance $\mathrm{X}$ flooding experience $=1.02, \mathrm{p}$-value $=0.33$ ) 
Table 3

Probit model of the likelihood of flood insurance purchase.

\begin{tabular}{|c|c|c|c|c|c|}
\hline & $\begin{array}{l}\text { Model I: Condition } \\
\text { and country } \\
\text { variables }\end{array}$ & $\begin{array}{l}\text { Model II: Including } \\
\text { flooding experience }\end{array}$ & $\begin{array}{l}\text { Model III: Including } \\
\text { insurance purchasing } \\
\text { experience }\end{array}$ & $\begin{array}{l}\text { Model IV: } \\
\text { Including risk } \\
\text { preference }\end{array}$ & $\begin{array}{l}\text { Model V: Including regret, } \\
\text { insurance cost, trust and } \\
\text { socio-economic variables }\end{array}$ \\
\hline UK dummy & $0.93^{* * * *}(0.11)$ & $0.91^{* * * *}(0.11)$ & $0.72^{* * *}(0.12)$ & $0.74^{* * *}(0.13)$ & $0.42^{* *}(0.16)$ \\
\hline Opt-out & $0.51^{* * * *}(0.11)$ & $0.54^{* * * *}(0.11)$ & $0.54^{* * *}(0.11)$ & $1.15^{* * * *}(0.24)$ & $1.16^{* * * *}(0.28)$ \\
\hline UK dummy $\mathrm{X}$ opt-out & $-0.52 * *(0.16)$ & $-0.39 *(0.17)$ & $-0.28(0.19)$ & $-0.31(0.19)$ & $-0.19(0.22)$ \\
\hline Flooding experience & & $0.36(0.27)$ & $-0.13(0.32)$ & $-0.14(0.32)$ & $0.57(0.37)$ \\
\hline Flooding experience $\mathrm{X}$ opt-out & & $-1.48^{* * *}(0.37)$ & $-1.08^{* *}(0.41)$ & $-1.05 *(0.42)$ & $-1.69 * * *(0.49)$ \\
\hline Hold insurance & & & $0.83^{* * * *}(0.23)$ & $0.82^{* * * *}(0.23)$ & $0.97^{* * *}(0.28)$ \\
\hline Hold insurance $\mathrm{X}$ opt-out & & & $-0.61 *(0.30)$ & $-0.55(0.30)$ & $-0.86 *(0.37)$ \\
\hline Held insurance & & & $0.53(0.42)$ & $0.50(0.42)$ & $0.46(0.46)$ \\
\hline Held insurance $\mathrm{X}$ opt-out & & & $-0.67(0.56)$ & $-0.51(0.56)$ & $-0.07(0.61)$ \\
\hline Risk preference & & & & $0.03(0.03)$ & $0.06(0.03)$ \\
\hline Risk preference $\mathrm{X}$ opt-out & & & & $-0.11^{* *}(0.04)$ & $-0.13^{* *}(0.04)$ \\
\hline Regret & & & & & $0.36^{* * *}(0.03)$ \\
\hline Insurance cost & & & & & $-0.32 * * *(0.03)$ \\
\hline Trust & & & & & $-0.11 * *(0.04)$ \\
\hline Age & & & & & $0.00(0.00)$ \\
\hline Male & & & & & $-0.06(0.10)$ \\
\hline Higher education & & & & & $-0.14(0.10)$ \\
\hline Constant & $0.04(0.07)$ & $0.03(0.07)$ & $0.03(0.07)$ & $-0.13(0.17)$ & $-0.15(0.41)$ \\
\hline Observations & 1187 & 1187 & 1187 & 1186 & 1132 \\
\hline Pseudo- $\mathrm{R}^{2}$ & 0.07 & 0.09 & 0.10 & 0.10 & 0.31 \\
\hline Log-likelihood & -653 & -642 & -634 & -628 & -466 \\
\hline
\end{tabular}

\section{Notes:}

Coefficient estimates are provided with standard errors in parentheses.

Observations are lower in model IV and V due to one subject not providing his/her risk preference and subjects providing their education level as "Other". *** Significant at $0.1 \%$.

** Significant at $1 \%$.

* Significant at $5 \%$.

preference $=0.09, \mathrm{p}$-value $=0.01$; coefficient estimate on opt-out $=1.47, \mathrm{p}$-value $=0.00$; coefficient estimate on risk preference $\mathrm{X}$ opt-out $=-0.26$, p-value $=0.00$ ).

One possible reason why we find that risk preference moderates the impact of the default in the UK, but not the Netherlands is that in the UK flood insurance demand is overall higher, so subjects who choose not to have it are perhaps making a more deliberate decision which should be identified by strong risk preferences. Fewer subjects in the Netherlands demand insurance, so there is in general a relative disinterest in it. Another potential explanation could be related to differences in flood risk perceptions. According to the analysis in Section 4, trust in flood defenses is much lower in the UK than the Netherlands. This may indicate that UK subjects have elevated flood risk perceptions, and risk preferences matter more for these subjects for which the risk of flooding is more salient. A subgroup of Dutch subjects who have low trust in flood defenses (using the median cut-off value we define these subjects as trust $<6$ ) are more likely to opt-out of flood coverage if they are more risk seeking, although this effect is only of marginal significance (Probit model coefficient estimate $=-0.11$, $\mathrm{p}$-value $=0.07$ ) probably because the subgroup is rather small, i.e., most Dutch subjects have high levels of trust in flood defenses.

\subsection{Regression analysis}

\subsubsection{Default effect in the Netherlands and the UK}

Table 3 provides a Probit model analysis of the likelihood of flood insurance purchase. Model I contains a dummy variable for UK subjects and opt-out as well as their interaction. Being a UK subject has overall a positive effect on flood insurance demand. The significant coefficient estimates on the opt-out dummy variable and its interaction with the UK dummy variable shows that on aggregate default assignment is only a predictor of flood insurance demand in the Netherlands. This shows the analysis in Fig. 2 numerically, that opt-out leads to a higher proportion of flood insurance purchase in the Netherlands where flood insurance demand and flooding experiences are low in practice, compared to opt-in, but opt-out has an insignificant influence on flood insurance purchase in the UK where penetration rates and flooding experiences are higher in practice.

Note that model I cannot shed light on whether country level differences in default effects are due to current or previous purchase of flood insurance (hold or held insurance) or flooding experience. To validate our use of the two countries as proxies for experience (with both flooding and purchasing flood insurance), we conducted additional regressions controlling for self-reported experience (models II and III). Validation would mean that adding these specific control variables to the regression, as well as their interaction with opt-out, eliminates the significant coefficient estimate on the opt-out and UK interaction term. After controlling for flooding experience and its interaction with opt-out (model II), there is still a significant coefficient estimate on the opt-out and UK interaction term, but the estimate is lower in magnitude and 
significance compared to model I. Moreover, opt-out has a negative impact on flood insurance demand for individuals with flooding experience, consistent with $\mathbf{H 3}$.

The interaction between opt-out and the UK dummy variable becomes insignificant once flooding experience and hold and held insurance as well as their interaction with opt-out have been controlled for (model III). In other words, once we control for these three variables, there is also a statistically significant default effect in the UK, meaning the default assignment to opt-out increases flood insurance demand. In addition, opt-out has a negative impact on flood insurance demand for individuals who state that they hold insurance currently, consistent with $\mathbf{H 2}$.

We also find that the positive effect of opt-out on flood insurance coverage is lower amongst more risk seeking subjects (model IV). This effect is presumably due to the interaction effect between risk preference and opt-out we find in the UK in Fig. 4.

Note that although we have explained the variance in default effects between the Netherlands and the UK with the experience variables, which is relevant for testing our hypotheses, there is still some variation left to explain regarding differences in flood insurance demand, because UK dummy remains a significant predictor. Some of this variation is explained in model $\mathrm{V}$ which controls for regret, insurance cost, trust and socio-economic variables. ${ }^{16}$ Responses to the regret question are skewed to the left (more so in the UK), indicating that a large proportion of subjects would regret uninsured flood losses (Appendix, Fig. A2), whereas responses to the insurance cost item are more normally distributed (Fig. A3). Responses to the trust item are more skewed to the left in the Netherlands than in the UK, indicating that a larger proportion of subjects have high levels of trust in flood defenses in the Netherlands, compared to the UK (Fig. A4). As expected, subjects who would feel regret about not purchasing flood insurance coverage if a flood were to occur next year are more likely to purchase flood insurance. Whereas, subjects who viewed the annual flood insurance cost as too expensive and have higher trust in flood defenses are less likely to purchase flood insurance.

\subsubsection{Mediation analysis}

We now examine mediators of the default effect we find in the Netherlands. Compared to subjects in the opt-in condition, those in the opt-out condition were significantly more likely to feel regret about not purchasing flood insurance coverage if a flood were to occur next year (Ordered Probit model coefficient estimate $=0.22$, p-value $=0.01$ ), and less likely to find the annual flood insurance cost too expensive (Ordered Probit model coefficient estimate $=-0.16$, p-value $=0.05$ ). Regret and insurance cost are also significantly related to the likelihood of flood insurance purchase in the Netherlands (Probit model coefficient estimates $=0.35$ and -0.27 , p-values $=0.00) .{ }^{17}$

Following Kohler et al. (2011), we examine the degree to which regret and insurance cost mediate the default effect. Their method provides unbiased decompositions of total effects into direct and indirect effects for nonlinear binary probability models, such as Probit. It has been shown to perform as well as, or better than other available methods (Breen et al., 2013).

Table 4 displays the total effect of opt-out on insurance demand divided into direct effect and indirect effect via regret and insurance cost using the Probit model. Overall, the opt-out condition increases the likelihood of insuring in the Netherlands by between 17 and 18 percentage points. Controlling for regret and insurance cost leaves a direct effect of between 11 and 12 percentage points. Therefore the indirect effect, which is the share of the relationship between opt-out and insurance demand which is due to regret and insurance cost is 6 percentage points. Approximately one-third (between 34 and 37 percent) of the relationship between opt-out and insurance demand is due to regret and insurance cost. ${ }^{18}$ Moreover, regret explains a larger proportion of this relationship than insurance cost. Insurance cost mediation becomes only marginally significant ( $p$-value $<0.1$ ) after including control variables, although this may be due to lower observations once control variables are included (see Table 4). The partial mediation we find is consistent with other default effects studies (Keller et al., 2011; Dinner et al., 2011). Partial mediation means that regret and insurance cost account for only some of the relationship between opt-out and flood insurance demand. It may also either indicate that our variables are a noisy measure of loss aversion, or that there are other mediating factors which are not accounted for in the analysis (Johnson et al., 2007).

\footnotetext{
${ }^{16}$ In a separate more elaborate regression model we find no interaction between regret, insurance cost, trust and opt-out (coefficient estimate on regret $=0.37$, $\mathrm{p}$-value $=0.00$; coefficient estimate on insurance cost $=-0.34$, p-value $=0.00$; coefficient estimate on trust $=-0.08, \mathrm{p}$-value $=0.11$; coefficient estimate on opt-out $=1.37$, p-value $=0.03$; coefficient estimate on regret $\mathrm{X}$ opt-out $=-0.02$, $\mathrm{p}$-value $=0.80$; coefficient estimate on insurance cost $\mathrm{X}$ optout $=0.05, \mathrm{p}$-value $=0.44$; coefficient estimate on trust $\mathrm{X}$ opt-out $=-0.06, \mathrm{p}$-value $=0.41$ ), therefore we choose to only include their main effects in Table 3.

17 In the UK, the influence of opt-out on regret is insignificant (Ordered Probit model coefficient estimate $=0.02$, $\mathrm{p}$-value $=0.81$ ), although regret is a positive predictor of flood insurance demand (Probit model coefficient estimate $=0.28, \mathrm{p}$-value $=0.00$ ). Perhaps opt-out does not impact regret in the UK because the average value is very high overall. There is also lower variation in the variable regret in the UK compared to in the Netherlands, and so less variation in regret to explain. Consistent with the Netherlands, UK subjects in the opt-out condition are less likely to find the annual flood insurance cost too expensive (Ordered Probit model coefficient estimate $=-0.23$, $\mathrm{p}$-value $=0.01$ ), and the variable insurance cost is negatively related to flood insurance demand (Probit model coefficient estimate $=-0.34$, p-value $=0.00$ ).

${ }^{18}$ In a separate mediation analysis for the UK, we find that after omitting subjects with previous flooding experience and those who report to currently hold flood insurance, as well as risk seeking subjects (defined as subjects who responded to the right of the central response category), the opt-out condition increases the likelihood of insuring in the UK by between 10 and 12 percentage points (Probit model p-values $<0.05$ ). Between 19 and 23 percent of the relationship is due to insurance cost, however this mediation is not significant ( $\mathrm{p}$-values $>0.05$ ) which may be due to the low number of observations (254) within this subgroup. Detecting mediated effects is typically challenging in small subgroups due to issues of statistical power (Fairchild and MacKinnon, 2009).
} 
Table 4

Decomposition of total effect of opt-out on flood insurance demand into direct effect and indirect effect via regret and insurance cost in the Netherlands using the Probit model.

\begin{tabular}{lll}
\hline & Without control variables & Including control variables \\
\hline Total effect & $0.18^{* * *}(0.03)$ & $0.17^{* * *}(0.03)$ \\
Direct effect & $0.12^{* * *}(0.03)$ & $0.11^{* * * *}(0.03)$ \\
Indirect effect & 0.06 & 0.06 \\
$\quad$ via regret & $0.04^{* *}(0.01)$ & $0.04^{* *}(0.01)$ \\
via insurance cost & $0.02^{*}(0.01)$ & $0.02(0.01)$ \\
Mediation percentage & 34 & 37 \\
$\quad$ via regret & 21 & 23 \\
$\quad$ via insurance cost & 13 & 14 \\
Observations & 599 & 586 \\
\hline
\end{tabular}

Notes:

Marginal effects are provided with standard errors in parentheses.

Standard errors of the overall indirect effect are not known.

Observations are lower with control variables due to one subject not providing his/her risk preference and subjects providing their education level as "Other".

Control variables are flooding experience, hold insurance, risk preference, trust, age, male and higher education. We do not control for held insurance due to insufficient observations.

*** Significant at $0.1 \%$.

** Significant at $1 \%$.

* Significant at $5 \%$.

\section{Discussion}

Section 6.1 provides a discussion of our results related to the hypotheses presented in Section 3, and Section 6.2 outlines some directions for future research.

\subsection{Hypotheses}

The present research demonstrates how default assignment can impact flood insurance demand. We find clear evidence that the opt-out condition increases the likelihood of insuring $(\mathbf{H 1})$ by between 17 and 18 percentage points in the Netherlands, where flood insurance penetration rates are currently low and flooding experiences are minor. However, there is no impact of the default on aggregate in the UK, where flood insurance purchasing and actual flooding experience are considerably higher than in the Netherlands. After controlling for these factors, the difference between the two countries becomes insignificant, providing validation of our use of country as a proxy for experience. Given that we show that UK homeowners who have purchased flood insurance and experienced flooding, purchase coverage more often in the opt-in than the optout condition, $\mathbf{H} \mathbf{2}$ and $\mathbf{H 3}$ are supported here (although the result is only marginally significant with respect to previous insurance purchasing experience). Note that it is not directly possible for us to discern whether the influence of previous insurance purchase experience results from exposure to the insurance problem or from the actual choice to buy insurance. We do not observe whether individuals were previously exposed to a flood insurance problem. Therefore, we cannot separate those who have not purchased flood insurance but thought about the problem, from those who have not thought about the problem. Nevertheless, the effects are consistent with studies showing that nudge policies may backfire amongst individuals who have pre-defined preferences across alternatives due to a perceived threat to their autonomy (Reiter et al., 2012; de Jonge et al., 2018).

Another result from the survey is that risk preferences moderate the default effect in the UK, since there is a default effect amongst risk averse, but not risk seeking subjects. We suspect that this may be because the general measure of risk preference we use is capturing loss aversion, which underlies the default effect. However, there is no moderation effect in the Netherlands. We suspect that this may be because risk preferences are relevant in countries where individuals have higher flood risk perceptions and a more general interest in flood insurance, which is the case in the UK.

We additionally show that subjects in the Netherlands in the opt-out condition were more likely to feel regret about not purchasing flood insurance coverage if a flood were to occur, and less likely to deem the annual flood insurance cost as too expensive. Subjects in the opt-out condition are likely to be more focused on the potential uninsured flood losses and the regret associated with not insuring, and place lower weight on the cost of insurance than those in the opt-in condition.

Subjects may also be less likely to deem the flood insurance cost as expensive in opt-out compared to opt-in because of mental accounting, according to which individuals use cognitive operations to organize, evaluate, and keep track of financial activities (Thaler, 1999). In opt-out, individuals may have explicitly designated the spent money as "insurance purchases", and perceive flood insurance coverage as a small portion of the total cost of the insurance policy, whereas individuals in opt-in may have labelled the money required to add flood coverage to the insurance policy differently e.g., "cash on hand". The unequal treatment of money, and in particular different marginal propensities for spending between mental accounts entails a violation of standard economic theory which assumes fungibility (Thaler, 1990). 
Together, the variables regret and insurance cost explain around one-third of the relationship between opt-out and flood insurance demand in the Netherlands, so $\mathbf{H 4}$ is supported here. These findings are consistent with the reference dependence and loss aversion account of the default effect found in some previous studies (Dinner et al., 2011; Johnson et al., 2007), as well as the influence of anticipated emotions in explaining anomalies like the endowment effect (Zhang and Fishbach, 2005; Kogler et al., 2013).

\subsection{Directions for future research}

Given that flooding events are uncommon, one may question whether it is ethical to nudge individuals towards more insurance. Without detailed information on individual consumers, such as their risks of flooding and preferences towards risk, any attempt to nudge individuals towards more coverage may be nudging the wrong way with respect to consumer welfare (Harrison and Ng, 2016). Some researchers have encouraged the use of "smart defaults" to overcome the ethical issues involved in nudging (Goldstein et al., 2008; Smith et al., 2013). Smart defaults collect consumer information (like socio-economic and geographic factors) to set default options in a way that is more likely to benefit individual consumers. For example, defaults may be set according to objective risk information like property elevation, distance to the nearest river and whether or not additional protection measures are in place. The use of smart defaults in the flood insurance market may provide a fruitful avenue for future research in order to achieve that those who need insurance coverage the most are likely to carry it.

The results from this study should also be replicated in a field experiment so that the data would be based on actual insurance purchases, rather than choices over a virtual insurance product. Even though a recent meta-analysis by Jachimowicz et al. (2019) found no difference in default effect sizes between field experiments and lab experiments, it is worthwhile to rule out that artificiality could be influencing behaviour (Harrison and List, 2004), and to examine how the effect sizes might change when it comes to choices in actual markets. Furthermore, it is an open question whether psychological reactance would occur if individuals were actually exposed to potentially high-impact losses by opting out of insurance. That is, it is uncertain to what extent the apparent reactance we find in our study is driven by the hypothetical nature of the choices. As an aside, we feel that a field experiment is a better route to take than a controlled experiment with incentivized decisions due to the practical issues associated with incentivizing high-impact losses.

\section{Conclusion}

Default assignment has been well researched in certain areas of decision making, like stimulating retirement saving, organ donation, pro-environmental choices and healthy eating. To the best of our knowledge there have been no studies on the impact of default options in the context of the insurance purchase decision for LPHI impacts such as damage to one's property from floods. Another novelty of our study is that we focus on whether past experience with respect to flood insurance purchase and past flood damage to one's property may moderate the impact of the default.

Our results reveal that providing flood insurance as a default option can be an effective way of increasing the insurance penetration rate in relatively new markets like the Netherlands. Raising the rates of insurance purchase may be seen as societally desirable in light of evidence that flood losses are predicted to rise in the future due to climate change. Moreover, in more established markets like the UK, there may exist subgroups of the population for which defaults are most effective if they are risk averse, and have no reported previous experience of flooding and purchasing flood insurance.

Our analysis suggests that defaults are effective in part due to the anticipated regret one might feel about not purchasing flood insurance coverage if a flood were to occur. Policymakers may design default flood insurance policies in a way that fosters this type of regret. That is, in addition to implementing flood insurance coverage as the default option, framing flood risk so that individuals pay attention to the worst-case scenario may be one such way. In particular, one might highlight the possible impact (monetary and/or psychological) of experiencing a catastrophic flood event uninsured to increase anticipated regret saliency.

\section{Declaration of Competing Interest}

The authors declare that they have no known competing financial interests or personal relationships that could have appeared to influence the work reported in this paper.

\section{Acknowledgments}

This study received financial support from the Netherlands Organisation for Scientific Research (NWO) VIDI Grant No. 452.14.005 and Alfred P. Sloan Foundation Grant No. G-2018-11100. 


\section{Appendix}
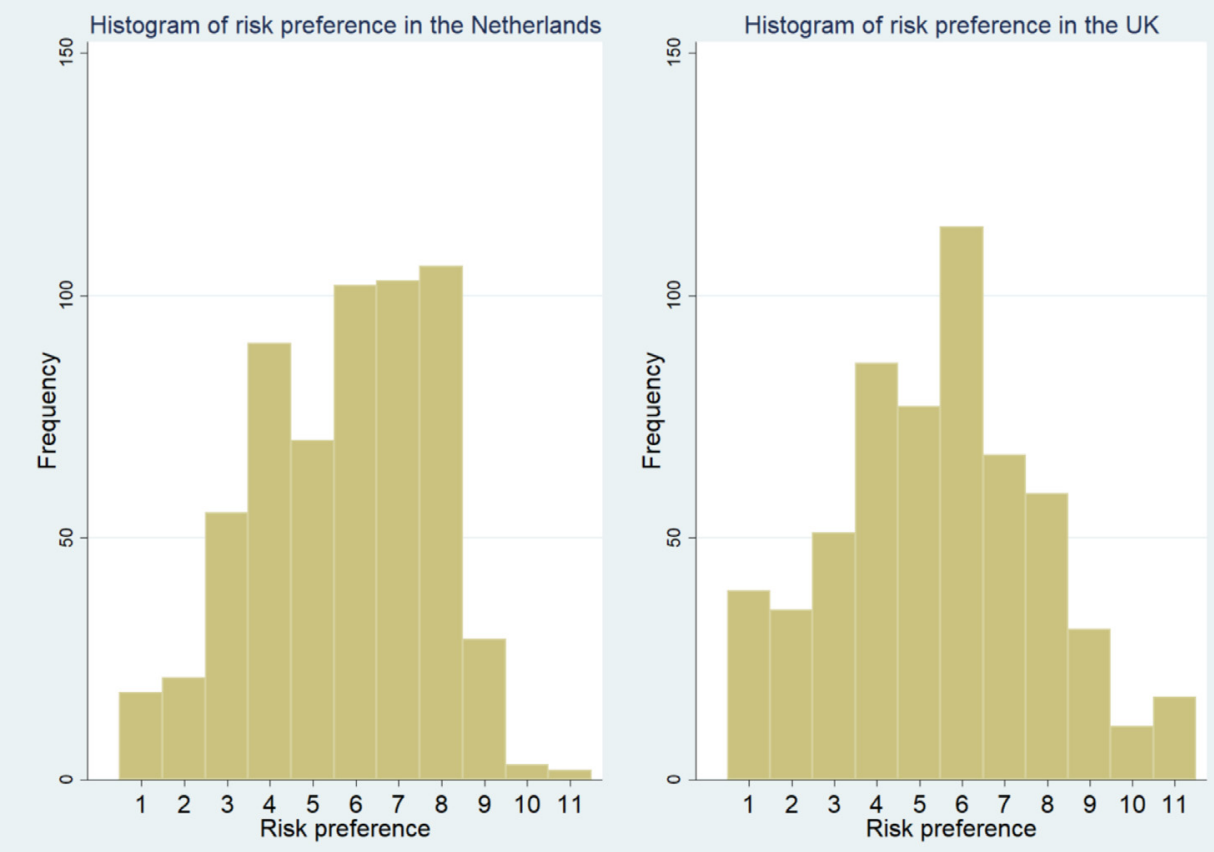

Fig. A1. Distribution of risk preference in the Netherlands and the UK Notes: higher values represent more risk seeking.

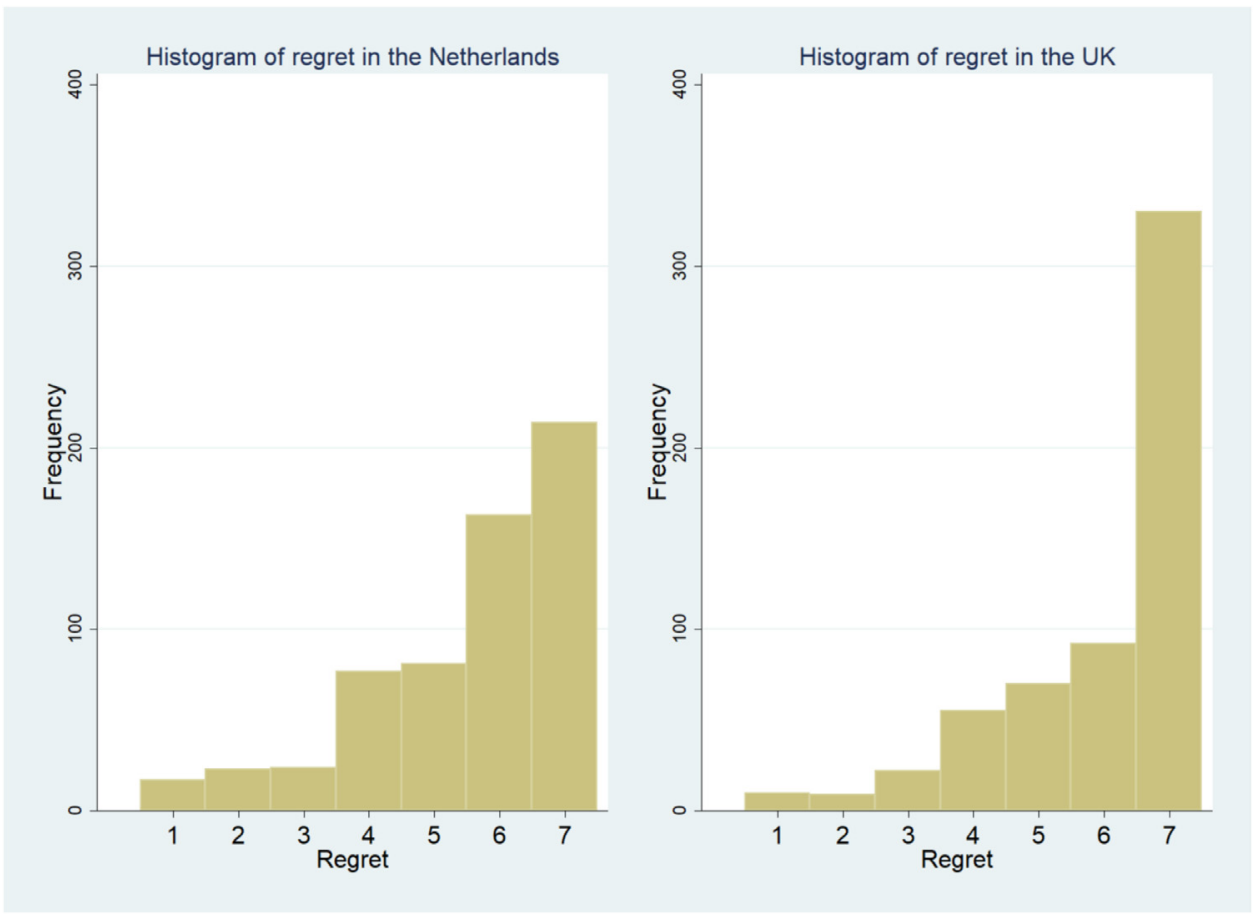

Fig. A2. Distribution of regret in the Netherlands and the UK. Notes: higher values represent more regret. 


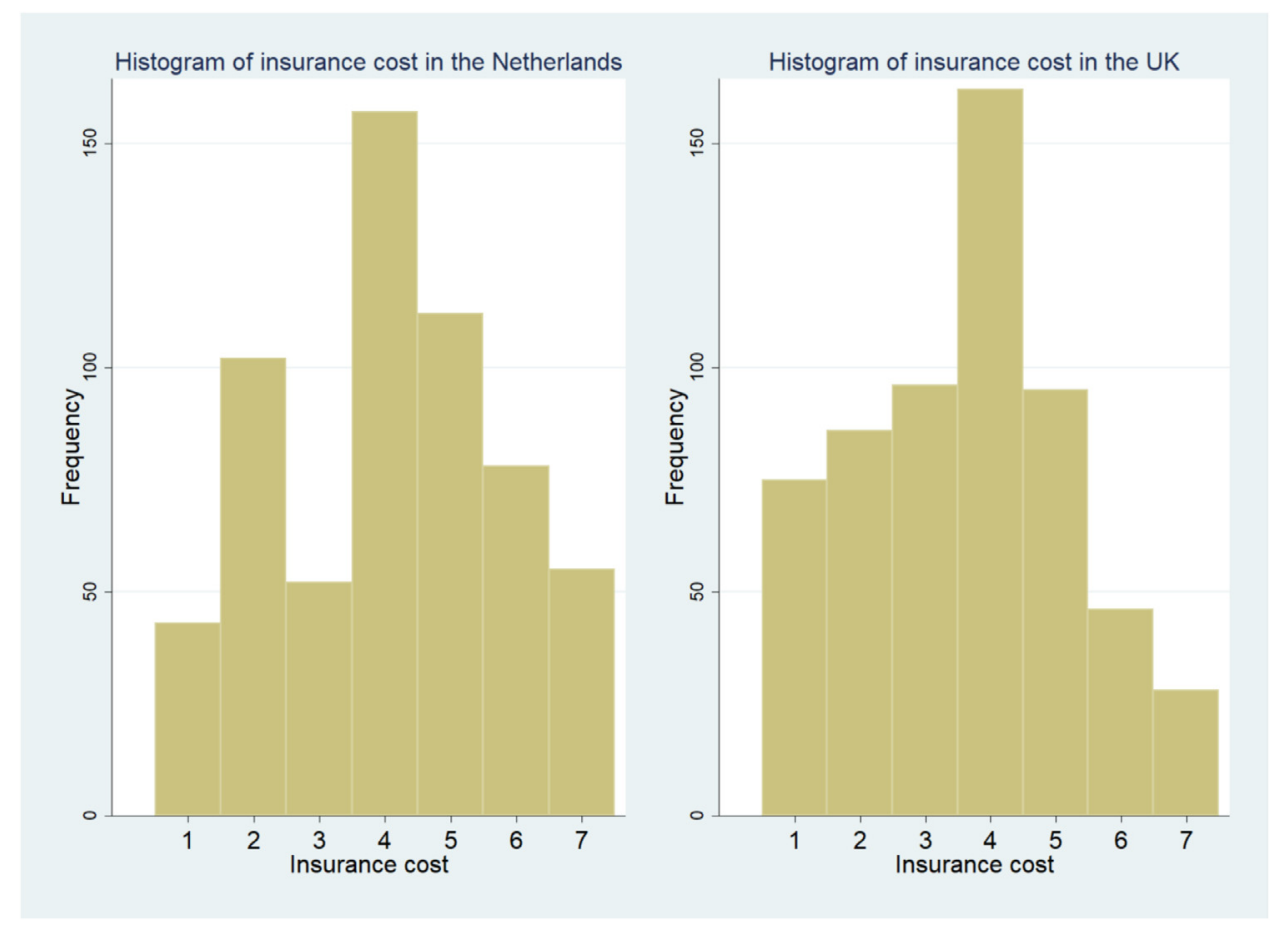

Fig. A3. Distribution of insurance cost in the Netherlands and the UK. Notes: higher values represent higher perceived insurance cost

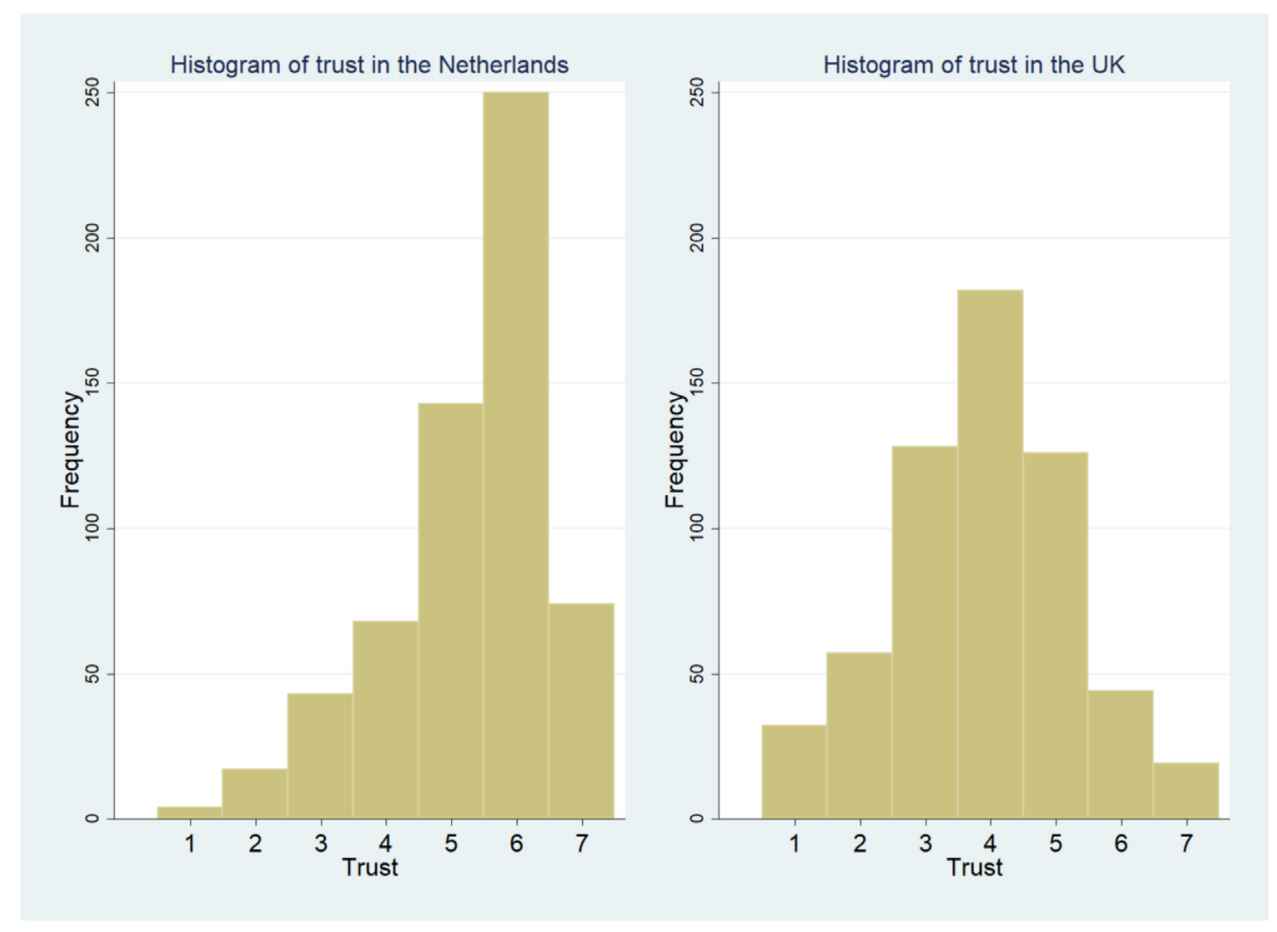

Fig. A4. Distribution of trust in the Netherlands and the UK. Notes: higher values represent more trust in flood defenses. 


\section{References}

Aerts, J.C., Botzen, W.W., 2011. Climate change impacts on pricing long-term flood insurance: a comprehensive study for the Netherlands. Global Environ. Change 21 (3), 1045-1060.

Andor, M.A., Osberghaus, D., Simora, M., 2020. Natural disasters and governmental aid: is there a charity hazard? Ecol. Econ. 169.

Bhargava, S., Loewenstein, G., 2015. Behavioral economics and public policy 102: beyond nudging. American Econ. Rev. 105 (5), $396-401$.

Bos, F., Zwaneveld, P., 2017. Cost-benefit Analysis For Flood Risk Management and Water Governance in the Netherlands: An overview of One Century. CPB Netherlands Bureau for Economic Policy Analysis.

Botzen, W.W., van den Bergh, J.C., 2009. Bounded rationality, climate risks, and insurance: is there a market for natural disasters. Land Econ. 85 (2), 265-278.

Botzen, W.W., van den Bergh, J.C., 2012. Risk attitudes to low-probability climate change risks: WTP for flood insurance. J. Econ. Behav. Organ. 82 (1), $151-166$

Bradt, J., 2019. Comparing the effects of behaviorally-informed interventions on flood insurance demand: an experimental analysis of 'boosts' and 'nudges. Behav. Public Policy. forthcoming. Available at SSRN https://ssrn.com/abstract=3424279 .

Breen, R., Karlson, K.B., Holm, A., 2013. Total, direct, and indirect effects in logit and probit models. Sociol. Methods Res. 42 (2), 164-191.

Brehm, J.W., 1966. A Theory of Psychological Reactance. Academic Press, Oxford, England.

Brown, J.R., Farrell, A.M., Weisbenner, S.J., 2016. Decision-making approaches and the propensity to default: evidence and implications. J. Financ. Econ. 121 (3), 477-495.

Browne, M.J., Knoller, C., Richter, A., 2015. Behavioral bias and the demand for bicycle and flood insurance. J. Risk Uncertain. 50 (2), 141-160.

Campitelli, G., Gerrans, P., 2014. Does the cognitive reflection test measure cognitive reflection? A mathematical modeling approach. Mem. Cognit. 42 (3), 434-447.

Chaudhry, S.J., Hand, M., Kunreuther, H., 2020. Broad bracketing for low probability events. J. Risk Uncertain.. forthcoming. Available at SSRN: https: //ssrn.com/abstract $=3537938$

Clee, M.A., Wicklund, R.A., 1980. Consumer behavior and psychological reactance. J. Consumer Res. 6 (4), 389-405.

Coe, N.B., Belbase, A., Wu, A.Y., 2016. Overcoming barriers to life insurance coverage: a behavioral approach. Risk Manag. Insurance Rev. 19 (2), $307-336$.

Cohen, J.F., Richardson, S.A., Cluggish, S.A., Parker, E., Catalano, P.J., Rimm, E.B., 2015. Effects of choice architecture and chef-enhanced meals on the selection and consumption of healthier school foods: a randomized clinical trial. JAMA Pediatr. 169 (5), $431-437$.

Cologna, V., Bark, R.H., Paavola, J., 2017. Flood risk perceptions and the UK media: moving beyond "once in a lifetime" to "be prepared" reporting. Climate Risk Manag. 17, 1-10.

de Jonge, P., Zeelenberg, M., Verlegh, P.W., 2018. Putting the public back in behavioral public policy. Behav. Public Policy 2 (2), $218-226$.

Dinner, I., Johnson, E.J., Goldstein, D., Liu, K., 2011. Partitioning default effects: why people choose not to choose. J. Exper. Psychol. 17 (4), 332.

Dohmen, T., Falk, A., Huffman, D., Sunde, U., Schupp, J., Wagner, G.G., 2011. Individual risk attitudes: measurement, determinants, and behavioral consequences. J. Eur. Econ. Assoc. 9 (3), 522-550.

Etchart-Vincent, N., 2009. Probability weighting and the 'level' and 'spacing' of outcomes: an experimental study over losses. J. Risk Uncertain. 39 (1), 45-63.

Fairchild, A.J., MacKinnon, D.P., 2009. A general model for testing mediation and moderation effects. Prev. Sci. 10 (2), 87-99.

Frederick, S., 2005. Cognitive reflection and decision making. J. Econ. Perspect. 19 (4), 25-42.

Goldstein, D.G., Johnson, E.J., Herrmann, A., Heitmann, M., 2008. Nudge your customers toward better choices. Harv. Bus. Rev. 86 (12), $99-105$.

Harrison, G.W., List, J.A., 2004. Field experiments. J. Econ. Lit. 42 (4), 1009-1055.

Harrison, G.W., Ng, J.M., 2016. Evaluating the expected welfare gain from insurance. J. Risk Insur. 83 (1), 91-120.

Hensher, D.A., Rose, J.M., Greene, W.H., 2005. Applied Choice analysis: A primer. Cambridge University Press.

HM Government, 2016. National flood resilience review. Available at: https://www.gov.uk/government/publications/national-flood-resilience-review

Huber, M., 2004. Insurability and regulatory reform: is the English flood insurance regime able to adapt to climate change?. The Geneva Papers on Risk and Insurance. Issues Practice 29 (2), 169-182.

Institute and Faculty of Actuaries, 2016. The future of UK flood policy: policy summary. Available at: https://www.actuaries.org.uk/news-and-insights/ media-centre/media-releases-and-statements/increased-spending-flood-defences-not-enough-solve-flooding-problems

Jachimowicz, J.M., Duncan, S., Weber, E.U., Johnson, E.J., 2019. When and why defaults influence decisions: a meta-analysis of default effects. Behav. Public Policy 3 (2), 159-186.

Johnson, E.J., Bellman, S., Lohse, G.L., 2002. Defaults, framing and privacy: why opting in-opting out. Mark. Lett. 13 (1), 5-15.

Johnson, E.J., Goldstein, D., 2003. Do defaults save lives? Science 302, 1338-1339.

Johnson, E.J., Häubl, G., Keinan, A., 2007. Aspects of endowment: a query theory of value construction. J. Exper. Psychol. 33 (3).

Johnson, E.J., Hassin, R., Baker, T., Bajger, A.T., Treuer, G., 2013. Can consumers make affordable care affordable? The value of choice architecture. PLoS ONE 8 (12).

Johnson, E.J., Hershey, J., Meszaros, J., Kunreuther, H., 1993. Framing, probability distortions, and insurance decisions. J. Risk Uncertain. 7 (1), 35-51.

Kahneman, D., Knetsch, J.L., Thaler, R.H., 1991. Anomalies: the endowment effect, loss aversion, and status quo bias. J. Econ. Perspect. 5 (1), $193-206$.

Kahneman, D., Tversky, A., 1979. Prospect theory: an analysis of decisions under risk. Econometrica 47.

Keller, P.A., Harlam, B., Loewenstein, G., Volpp, K.G., 2011. Enhanced active choice: a new method to motivate behavior change. J. Consum. Psychol. 21 (4), 376-383.

Kogler, C., Kühberger, A., Gilhofer, R., 2013. Real and hypothetical endowment effects when exchanging lottery tickets: is regret a better explanation than loss aversion? J. Econ. Psychol. 37, 42-53.

Kohler, U., Karlson, K.B., Holm, A., 2011. Comparing coefficients of nested nonlinear probability models. Stata J. 11 (3), $420-438$.

Kousky, C., 2018. Financing flood losses: a discussion of the national flood insurance program. Risk Manag. Insurance Rev. 21 (1), 11-32.

Krieger, M., Felder, S., 2013. Can decision biases improve insurance outcomes? An experiment on status quo bias in health insurance choice. Int. J. Environ. Res. Public Health 10 (6), 2560-2577.

Kunreuther, H., 2015. The role of insurance in reducing losses from extreme events: the need for public-private partnerships. Geneva Papers Risk Insur.-Issues Practice 40 (4), 741-762.

Kunreuther, H., Novemsky, N., Kahneman, D., 2001. Making low probabilities useful. J. Risk Uncertain. 23 (2), $103-120$.

Kunreuther, H., Pauly, M., 2004. Neglecting disaster: why don't people insure against large losses. J. Risk Uncertain. 28 (1), 5-21.

Kunreuther, H., Pauly, M., 2018. Dynamic insurance decision-making for rare events: the role of emotions. Geneva Papers Risk Insur.-Issues Practice 43 (2), $335-355$.

List, J.A., 2003. Does market experience eliminate market anomalies? Q. J. Econ. 118 (1), 41-71.

List, J.A., 2004. Neoclassical theory versus prospect theory: evidence from the marketplace. Econometrica 72 (2), $615-625$.

Löfgren, A., Martinsson, P., Hennlock, M., Sterner, T., 2012. Are experienced people affected by a pre-set default option-results from a field experiment. J. Environ. Econ. Manage. 63 (1), 66-72.

McCarthy, M., Spillane, S., Walsh, S., Kendon, M., 2016. The meteorology of the exceptional winter of 2015/2016 across the UK and Ireland. Weather 71 (12), 305-313.

McKenzie, C.R., Liersch, M.J., Finkelstein, S.R., 2006. Recommendations implicit in policy defaults. Psychol. Sci. 17 (5), $414-420$.

Meyer, R., Kunreuther, H., 2017. The Ostrich paradox: Why we Underprepare For Disasters. Wharton Digital Press, Philadelphia, PA.

Muchan, K., Lewis, M., Hannaford, J., Parry, S., 2015. The winter storms of 2013/2014 in the UK: hydrological responses and impacts. Weather 70 (2), 55-61. 
Paudel, Y., Botzen, W.W., Aerts, J.C., 2012. A comparative study of public-private catastrophe insurance systems: lessons from current practices. Geneva Papers Risk Insur.-Issues Practice 37 (2), 257-285.

Pavey, L., Sparks, P., 2009. Reactance, autonomy and paths to persuasion: examining perceptions of threats to freedom and informational value. Motiv. Emot. 33 (3), 277-290

Penning-Rowsell, E.C., 2014. The 2013/14 floods: what do they tell us about overall flood risk in England and Wales. Circulation 121.

Penning-Rowsell, E.C., Priest, S.J., 2015. Sharing the burden of increasing flood risk: who pays for flood insurance and flood risk management in the United Kingdom. Mitigat. Adapt. Strat. Global Change 20 (6), 991-1009.

Penning-Rowsell, E.C., Priest, S., Johnson, C., 2014. The evolution of UK flood insurance: incremental change over six decades. Int. J. Water Resour. Dev. 30 (4), 694-713.

Pitt, M., 2008. Learning Lessons from the 2007 Floods: An Independent Review by Sir Michael Pitt. Cabinet Office, London.

Plott, C.R., Zeiler, K., 2005. The willingness to pay-willingness to accept gap, the "endowment effect", subject misconceptions, and experimental procedures for eliciting valuations. Am. Econ. Rev. 95 (3), 530-545.

Prelec, D., Loewenstein, G., 1998. The red and the black: mental accounting of savings and debt. Mark. Sci. 17 (1), 4-28.

Reiter, P.L., McRee, A.L., Pepper, J.K., Brewer, N.T., 2012. Default policies and parents' consent for school-located HPV vaccination. J. Behav. Med. 35 (6), 651-657.

Robinson, P.J., Botzen, W.W., 2019. Flood insurance demand and probability weighting: the influences of regret, worry, locus of control and the threshold of concern heuristic. Water Res. Econ. in press.

Samuelson, W., Zeckhauser, R., 1988. Status quo bias in decision making. J. Risk Uncertain. 1 (1), 7-59.

Sautua, S.I., 2017. Does uncertainty cause inertia in decision making? An experimental study of the role of regret aversion and indecisiveness. J. Econ. Behav. Organ 136, 1-14.

Smith, N.C., Goldstein, D., Johnson, E.J., 2013. Choice without awareness: ethical and policy implications of defaults. J. Public Policy Mark. 32 (2), 159-172.

Statistics Netherlands, 2018. StatLine Database. Centraal Bureau voor de Statistiek.

Sugden, R., 2003. Reference-dependent subjective expected utility. J. Econ. Theory 111 (2), 172-191.

Sunstein, C.R., 2013. Deciding by default. Univ. PA Law Rev. 162.

Surminski, S., 2018. Fit for purpose and fit for the future? An evaluation of the UK's new flood reinsurance pool. Risk Manag. Insur. Rev. 21 (1), 33-72.

Surminski, S., Aerts, J.C., Botzen, W.W., Hudson, P., Mysiak, J., Pérez-Blanco, C.D., 2015. Reflections on the current debate on how to link flood insurance and disaster risk reduction in the European Union. Nat. Hazards 79 (3), 1451-1479.

Surminski, S., Eldridge, J., 2017. Flood insurance in England-an assessment of the current and newly proposed insurance scheme in the context of rising flood risk. J. Flood Risk Manage. 10 (4), 415-435.

Suykens, C.B.R., Priest, S., van Doorn-Hoekveld, W.J., Thuillier, T., van Rijswick, H.F.M.W., 2016. Dealing with flood damages: will prevention, mitigation, and ex post compensation provide for a resilient triangle? Ecol. Soc. 21 (4).

Terpstra, T., 2011. Emotions, trust, and perceived risk: affective and cognitive routes to flood preparedness behavior. Risk Anal. 31 (10), $1658-1675$.

Thaler, R.H., 1999. Mental accounting matters. J. Behav. Decis. Mak. 12 (3), 183-206.

Thaler, R.H., 1990. Anomalies: saving, fungibility, and mental accounts. J. Econ. Perspect. 4 (1), 193-205.

Thaler, R.H., 1980. Toward a positive theory of consumer choice. J. Econ. Behav. Organ 1 (1), 39-60.

Thaler, R.H., Johnson, E.J., 1990. Gambling with the house money and trying to break even: the effects of prior outcomes on risky choice. Manage. Sci. 36 (6), 643-660.

Thaler, R.H., Sunstein, C.R., 2008. Nudge: Improving decisions About health, wealth, and Happiness. Yale University Press, New Haven.

Thomson, K.S., Oppenheimer, D.M., 2016. Investigating an alternate form of the cognitive reflection test. Judgm. Decis. Mak. 11 (1).

Tversky, A., Kahneman, D., 1974. Judgment under uncertainty: heuristics and biases. Science 185 (4157), 1124-1131.

Tversky, A., Kahneman, D., 1992. Advances in prospect theory: cumulative representation of uncertainty. J. Risk Uncertain. 5 (4), 297-323.

Ungemach, C., Camilleri, A.R., Johnson, E.J., Larrick, R.P., Weber, E.U., 2017. Translated attributes as choice architecture: aligning objectives and choices through decision signposts. Manage Sci. 64 (5), 2445-2459.

Wakker, P.P., 2010. Prospect theory: For Risk and Ambiguity. Cambridge University Press.

Wallemacq, P., 2018. Economic Losses, Poverty \& Disasters: 1998-2017. Centre for Research on the Epidemiology of Disasters, CRED.

Weller, J.A., Dieckmann, N.F., Tusler, M., Mertz, C.K., Burns, W.J., Peters, E., 2013. Development and testing of an abbreviated numeracy scale: a Rasch analysis approach. J. Behav. Decis. Mak. 26 (2), 198-212.

Wouters, K., 2005. Veiligheid Nederland in Kaart Globale Schadeberekening: Achtergronddocument. Rijkswaterstaat, Delft.

Zhang, Y., Fishbach, A., 2005. The role of anticipated emotions in the endowment effect. J. Consum. Psychol. 15 (4), 316-324. 